DR ADAM HUCZYŃSKI (Orcid ID : 0000-0003-4770-215X)

DR DIETMAR STEVERDING (Orcid ID : 0000-0002-0050-7771)

Article type : Research Article

\title{
Cytotoxic and Trypanocidal Activities of Cinchona Alkaloid Derivatives
}

\section{Karol Kacprzak $^{1}$, Piotr Ruszkowski ${ }^{2}$, Luisa Valentini ${ }^{3}$, Adam Huczyński ${ }^{1}$, Dietmar Steverding ${ }^{3}$}

${ }^{1}$ Bioorganic Chemistry Department, Faculty of Chemistry, Adam Mickiewicz University, Poznan, Poland

${ }^{2}$ Department of Pharmacology, Poznan University of Medical Sciences, Poznan, Poland ${ }^{3}$ Bob Champion Research \& Education Building, Norwich Medical School, University of East Anglia, Norwich, United Kingdom

Short running title: Cinchona alkaloid derivatives as drug candidates

\section{Correspondence}

Dietmar Steverding, Bob Champion Research \& Education Building, Norwich Medical School, University of East Anglia, Norwich NR4 7UQ, United Kingdom

Tel.: 441603591291

Fax: 441603593752

Email: d.steverding@uea.ac.uk

This article has been accepted for publication and undergone full peer review but has not been through the copyediting, typesetting, pagination and proofreading process, which may lead to differences between this version and the Version of Record. Please cite this article as doi: $10.1111 /$ cbdd.13346

This article is protected by copyright. All rights reserved. 


\begin{abstract}
A series of 27 cinchona alkaloid derivatives (1f-w, 2a-e and 3a-d) were investigated for their cytotoxic and trypanocidal activities using seven different cancer cell lines (KB, HeLa, MCF7, A-549, Hep-G2, U-87 and HL-60), two normal cell lines (HDF and CHO) and bloodstream forms of Trypanosoma brucei brucei, respectively. Four compounds (1u, 1w, 2e and 3d) were identified with promising cytotoxic activity with $50 \%$ growth inhibition $\left(\mathrm{GI}_{50}\right)$ values below $10 \mu \mathrm{M}$. Two (2e and $\mathbf{3 d}$ ) of the four compounds also exhibited potent antitrypanosomal activity with $\mathrm{GI}_{50}$ values of $0.3-0.4 \mu \mathrm{M}$. All four active compounds represented derivatives modified at their C-9 hydroxy group. With respect to anti-proliferative activity and selectivity, 2e (epi- $N$-quinidyl- $N$ '-bis(3,5-trifluoromethyl)phenylthiourea) proved to be the most promising derivative for both cancer cells and bloodstream forms of T. b. brucei. The cytotoxic activity of compounds $1 \mathbf{u}, \mathbf{1 w}, \mathbf{2 e}$ and $\mathbf{3 d}$ was attributed to their ability to induce apoptosis in cancer cells. The results demonstrate the potential of cinchona alkaloid derivatives as novel anti-cancer and anti-trypanosome drug candidates.
\end{abstract}

\title{
KEYWORDS
}

cinchona alkaloids, human cancer cells, Trypanosoma brucei, cytotoxicity, trypanotoxicity

\section{INTRODUCTION}

The bark of the cinchona tree (Cinchona sp.) contains many bioactive quinoline-type alkaloids. Among them, quinine is both the most important and best known alkaloid of this class of natural compounds. Historically, quinine was the sole cure for malaria for centuries until the introduction of the synthetic analogue chloroquine after World War II. Other major alkaloids found in the cinchona bark are the closely related compounds quinidine, cinchonine and cinchonidine, which together with quinine are collectively classified as 'cinchona alkaloids'.

This article is protected by copyright. All rights reserved. 
Apart from their utilization as anti-malaria agents, cinchona alkaloids are also deployed to treat intestinal parasites, arrhythmia and other heart conditions, nocturnal leg cramps, and fever, and are used as a bitter digestive aid. ${ }^{[1,2]}$ In addition, cinchona alkaloids have been reported to be inhibitors of the P-glycoprotein, a membrane transporter that is overexpressed on tumour cells and responsible for the process of efflux of chemotherapeutics. For example, cinchonine has been shown to improve the accumulation of doxorubicin in cancer cells. ${ }^{[3]}$ Moreover, cinchonine and quinine were found to induce apoptosis in cancer cells and thus inhibit their proliferation. ${ }^{[4,5]}$ Furthermore, cinchona alkaloids have been reported to display trypanocidal activity against bloodstream forms of Trypanosoma brucei and T. congolense with $50 \%$ growth inhibition $\left(\mathrm{GI}_{50}\right)$ values in the mid to low micromolar range. ${ }^{[6]}$ These flagellated protozoan parasites are the causative agents of sleeping sickness in humans and nagana disease in cattle, and are transmitted by the bite of infected tsetse flies. African trypanosomiasis is one of the most neglected tropical diseases and throughout history, it has severely repressed the economic and cultural development of central Africa. ${ }^{[7]}$ As the few currently available chemotherapies of sleeping sickness and nagana disease are unsatisfactory, ${ }^{[8]}$ new and effective drugs are needed for treatment of African trypanosomiasis.

The previous findings that native cinchona alkaloids have anti-cancer and antitrypanosomal properties prompted us to investigate whether the cytotoxic and trypanocidal activities of this class of natural products can be improved by their modification. In this study we report the cytotoxic and trypanocidal activities of 27 cinchona alkaloid derivatives (Table 1) of which 8 were commercially available (1f-h, $\mathbf{2 a - e})$ and 19 were synthesised (1i-w, 3a-d) according to published methods. ${ }^{[9-16]}$

This article is protected by copyright. All rights reserved. 


\section{MATERIALS AND METHODS}

\subsection{Reagents}

Unmodified cinchona alkaloids 1a-e and their hydrogenated analogues $\mathbf{1 f}-\mathbf{h}$ and $\mathbf{1 k}$ were purchased from Buchler GmbH (Braunschweig, Germany) or Sigma-Aldrich (Poznan, Poland). 9-Amino-9-epi-cinchona derivatives 2a-d and the thiourea $2 \mathbf{e}$ were bought from AdvaChemLab (Poznan, Poland). All other reagents required for organic synthesis and toxicity assays were obtained from Sigma-Aldrich (Poznan, Poland and Gillingham, U.K., respectively) and Fluorochem (Hadfield, U.K.) and used as received.

\subsection{Chemistry}

NMR spectra were recorded at $295 \mathrm{~K}$ on a Bruker Ascend $400 \mathrm{MHz}$ spectrometer, operating at frequencies of $400 \mathrm{MHz}$ for ${ }^{1} \mathrm{H}$ and $101 \mathrm{MHz}$ for ${ }^{13} \mathrm{C}$. All shifts were referenced to the internal tetramethylsilane. Mass spectra were determined on a Bruker Impact HD instrument. IR spectra were recorded using $\mathrm{KBr}$ pellets on a Brucker FT-IR IFS-66/s spectrometer.

Dihydrocupreines 1i-j, 10,11-didehydrocinchona alkaloids 11-m, cinchotenine derivatives 1n-p and deoxyhydroquinidine 1q were prepared as previously described. ${ }^{[9-12]}$ Quinine esters 1r-s and 9- $O$-carbamates 1t-w were synthesised using general procedures. ${ }^{[13,14]}$ Quaternary ammonium salts 3a-c were prepared by reaction of quinine with 9-anthracenylmethyl chloride or appropriate benzyl halides as previously reported while the salt $\mathbf{3 d}$ was obtained following a previous published protocol. ${ }^{[15,16]}$ All compounds were properly characterized and their purity was $>95 \%$.

\subsection{Cells}

$\mathrm{KB}, \mathrm{HeLa}, \mathrm{MCF}-7, \mathrm{Hep}-\mathrm{G} 2$ and $\mathrm{CHO}$ cells were obtained from the European Collection of Cell Culture (ECACC) supplied by Sigma Aldrich (Poznan, Poland). A-549, U-87, HDF and HL-60 cells were purchased from the American Type Culture Collection (ATCC) through LGC Standards (Lomianki, Poland and Teddington, U.K., respectively). Bloodstream forms of T. b. brucei 427-221a were previously obtained from the Wellcome Centre for Molecular 
Parasitology (Glasgow, U.K.). This subspecies is non-pathogenic to humans but morphological and biochemical indistinguishable from the human pathogenic subspecies T. $b$. gambiense and T. b. rhodesiense.

\subsection{Cell culture and in vitro toxicity assay}

\subsubsection{Tumour and normal cells}

$\mathrm{KB}$, Hep-G2 and U-87 cells were cultured in EMEM medium while HeLa cells were grown in RPMI 1640 medium, A-549 and CHO cells in F-12K medium, MCF-7 cells in DMEM medium, U-87 in EMEM medium and HDF cells in Fibroblasts Growth Medium. Each medium was supplemented with $10 \%$ foetal bovine serum, $1 \%$ L-glutamine and $1 \%$ penicillin/streptomycin solution (final concentrations $100 \mathrm{U} / \mathrm{ml}$ penicillin and $100 \mu \mathrm{g} / \mathrm{ml}$ streptomycin). All cultures were maintained at $37^{\circ} \mathrm{C}$ in a humidified atmosphere containing $5 \% \mathrm{CO}_{2}$.

For determining the cytotoxic activity of test compounds, the protein-staining sulforhodamine B (SRB) assay and/or the tetrazolium reduction (MTT) assay were employed. Both assays have been assessed by the National Cancer Institute (USA) as suitable for in vitro anti-tumour screening. ${ }^{[17]}$ The SRB and the MTT assay estimate cell densities based on measurement of cellular protein content and activity of oxidoreductase enzymes, respectively. For the SRB assay, $100 \mu 1$ of diluted cell suspension containing approximately $10^{4}$ cells was added to the wells of 96-well plates. After $24 \mathrm{~h}$, when a partial monolayer had formed, the supernatant was aspirated and $100 \mu 1$ medium containing test compounds at six different concentrations $(0.1,0.2,1,2,10$ and $20 \mu \mathrm{g} / \mathrm{ml})$ was added to the cells. Stock solutions of test compounds were prepared in DMSO and the concentration of DMSO in the assay did not exceed $0.1 \%$ which was found to be nontoxic to the different cell lines. After incubation for $72 \mathrm{~h}, 25 \mu \mathrm{l}$ of $50 \%$ trichloroacetic acid was added to each well and the plates were incubated for $1 \mathrm{~h}$ at $4^{\circ} \mathrm{C}$. Thereafter, the plates were washed with distilled water to remove traces of medium and air-dried. Then, the dried plates were stained with $100 \mu 10.4 \%$ SRB (prepared in 
$1 \%$ acetic acid) for $30 \mathrm{~min}$ at room temperature. Unbound dye was removed by rapidly washing with $1 \%$ acetic acid and the plates were air-dried overnight. Finally, the proteinbound dye was dissolved in $100 \mu \mathrm{l}$ of $10 \mathrm{mM}$ unbuffered Tris and the absorbance read at 490 nm.

For the MTT assay, $180 \mu \mathrm{l}$ of suspended cells $\left(2 \times 10^{4} / \mathrm{mL}\right)$ was pipetted into the wells of 96-well plates. After $24 \mathrm{~h}$ incubation, $20 \mu \mathrm{l}$ of test compounds was added (final concentrations of $0.1,0.2,1,2,10$ and $20 \mu \mathrm{g} / \mathrm{ml}$ ) and the plates were incubated for another 48 h. Then, $10 \mu \mathrm{l}$ of $5 \mathrm{mg} / \mathrm{ml}$ MTT solution was added to each well and the plates incubated for additional $3 \mathrm{~h}$. The formed formazan crystals were dissolved in $100 \mu 110 \%$ sodium dodecyl sulphate (SDS) solution and the absorbance measured at $545 \mathrm{~nm}$.

The concentration of a compound required to inhibit cell growth by $50 \%$ (half-maximal growth inhibition; $\mathrm{GI}_{50}$ ) compared to the control was calculated using GraphPad Prism software.

\subsubsection{Trypanosomes and HL-60 cells}

Bloodstream forms of the non-human pathogenic subspecies T. b. brucei (clone 427-221a ${ }^{[18]}$ ) and human myeloid leukaemia HL-60 cells ${ }^{[19]}$ were grown in Baltz medium ${ }^{[20]}$ supplemented with $16.7 \%$ heat-inactivated bovine serum at $37^{\circ} \mathrm{C}$ in a humidified atmosphere. Toxicity assays with trypanosomes and HL-60 cells were carried out as previously described ${ }^{[6]}$ with some modifications. In brief, cells were seeded in 96-well plates in a final volume of $200 \mu 1$ of Baltz medium containing test compounds serially diluted tenfold from $100 \mu \mathrm{M}$ down to $100 \mathrm{pM}$ and 1\% DMSO. Wells just containing medium and 1\% DMSO served as controls. The initial cell densities were $1 \times 10^{4} / \mathrm{ml}$ for trypanosomes and $5 \times 10^{4} / \mathrm{ml}$ for HL- 60 cells. After $24 \mathrm{~h}$ incubation, $20 \mu \mathrm{l}$ of a $0.5 \mathrm{mM}$ resazurin solution prepared in sterile PBS was added and the cells were incubated for a further $48 \mathrm{~h}$. Thereafter, the absorbance of wells was read at $570 \mathrm{~nm}$ (test wavelength) and $630 \mathrm{~nm}$ (reference wavelength). The $\mathrm{GI}_{50}$ value, i.e., the 
concentration of a compound necessary to reduce the growth rate of cells by $50 \%$ compared to the control was determined by linear interpolation as described previously. ${ }^{[21]}$ The minimum inhibitory concentration (MIC) values, i.e. the concentration of the drug at which all trypanosomes and human cells were killed, was determined microscopically.

\subsection{Apoptosis Assay}

The induction of apoptosis by test compounds was determined with the Cell Death Detection ELISA $^{\text {PLUS }}$ from Roche Diagnostics GmbH (Mannheim, Germany). This is an enzyme immunoassay for the determination of cytoplasmic histone-associated DNA fragments (mono- and oligonucleotides) after induced cell death. Cells $\left(10^{4}\right)$ were pipetted into wells of 96-well plates and test compounds added at final concentrations of $0.1,1$ and $10 \mu \mathrm{g} / \mathrm{ml}$. Cells incubated in the absence of test compounds served as negative controls. After $4 \mathrm{~h}$ incubation, cells were harvested by centrifugation of the plates for $10 \mathrm{~min}$ at $200 \times g$. Supernatants were removed carefully and cell pellets re-suspended in $200 \mu 1$ lysis buffer and incubated for 30 min at room temperature. After centrifugation of the plates $(10 \mathrm{~min}, 200 \times g), 20 \mu 1$ of cell lysates were transferred in duplicate into wells of provided streptavidin-coated microplates. Then, $80 \mu 1$ of the immunoreagent containing a mixture of anti-histone-biotin monoclonal antibody and anti-DNA-peroxidase monoclonal antibody was added to each well. The microplates were covered with a provided adhesive foil and incubated for $2 \mathrm{~h}$ at room temperature. Thereafter, the solution in the wells was removed by tapping the microplate. The wells were rinsed three times with incubation buffer and $100 \mu 1$ of substrate (2,2'-azino-bis(3ethylbenzothiazoline-6-sulphonic acid, ABTS) was added to each well. After 10-20 min, 100 $\mu \mathrm{l}$ of ABTS stop solution was pipetted to each well and the absorbance was read at $405 \mathrm{~nm}$ (test wavelength) and $490 \mathrm{~nm}$ (reference wavelength). The apoptotic index was calculated based on the enrichment of mono- and oligonucleosomes according to the following equation:

apoptotic index $=\left[\left\{\mathrm{A}_{405(\text { sample) }}-\mathrm{A}_{490(\text { sample) }}\right\} \div\left\{\mathrm{A}_{405 \text { (negative control) }}-\mathrm{A}_{490 \text { (negative control) }}\right\}\right]$. 


\section{RESULTS AND DISCUSSION}

\subsection{Cytotoxicity of cinchona alkaloid derivatives}

The cytotoxic activities of unmodified (1a-e) and derivatized (1f-u, 1w, 2a-c, 2e, 3d) cinchona alkaloids were evaluated with six human tumour cell lines (KB: cervix carcinoma derived from HeLa cells ${ }^{\text {a }}$; HeLa: cervix carcinoma; MCF-7: breast cancer; A-549: lung cancer; Hep-G2: liver cancer; U-87, glioblastoma) and two normal cell lines (HDF: human dermal fibroblast; CHO: Chinese hamster ovary cells) using the SRB and/or the MTT assay. The unmodified cinchona alkaloids 1a-c were not very cytotoxic with $\mathrm{GI}_{50}$ (half-maximal growth inhibition) values ranging from $36.4 \mu \mathrm{M}$ to $155 \mu \mathrm{M}$ for tumour cells and from 111 $\mu \mathrm{M}$ to $397 \mu \mathrm{M}$ for normal cells (Table 2). Similar cytotoxicity values have been previously reported for quinine and $\mathrm{KB}$ cells $\left(\mathrm{GI}_{50}=118 \mu \mathrm{M}\right.$; our study $\left.55.5 \mu \mathrm{M}\right)$ and for cinchonine and HeLa cells $\left(\mathrm{GI}_{50}=180 \mu \mathrm{M}\right.$; our study $\left.155 \mu \mathrm{M}\right) .{ }^{[4,5]}$ Cinchona alkaloid molecules with an ethyl, an ethynyl or a carboxyl group (1f-p) instead of the vinyl group displayed similar cytotoxic activities as their unmodified counterparts (Table 2). This finding suggests the vinyl group to be non-essential to the cytotoxic action of cinchona alkaloids. On the other hand, some compounds with a modified C-9 hydroxy group showed improved cytotoxicities compared to the unmodified precursors. While compounds without a C-9 hydroxy group (1q) or with an esterified C-9 hydroxy group (1r-s) did not show increased cytotoxic activities, two 9-O-carbamates (1u and $\mathbf{1 w}$ ) displayed improved cytotoxicities with $\mathrm{GI}_{50}$ values in the low-micromolar range (Table 2). A 9-O-allyl cinchonidine derivative (3d) which was additionally quaternized at the quinuclidine nitrogen with a bulky 9-methylanthracene substituent (note that single modification of this position with a 9-methylanthracene substituent (3a) already increases the cytotoxic activity of cinchona alkaloids slightly; see below and Table 4) exhibited cytotoxic activities with $\mathrm{GI}_{50}$ values in the low-micromolar range as well (Table 2). Furthermore, compounds with a C-9 amino group of inverted absolute configuration instead of the native C-9 hydroxy group (2a-c) showed slightly improved cytotoxic activities ( 4-fold lower $\mathrm{GI}_{50}$ value; Table 2). A 9-amino-9-epi-quinidine derivative in which the amino group was transformed into a 3,5-bis(trifluoromethyl) 
phenylthiourea substituent (2e) exhibited further enhanced cytotoxicity with $\mathrm{GI}_{50}$ values in the low- and mid-micromolar range for tumour and normal cells, respectively (Table 2).

Derivatives 1u, 1w, 2e and 3d were identified as the most toxic compounds for all cancer cells with $\mathrm{GI}_{50}$ values $<10 \mu \mathrm{M}$. As the reliability of cytotoxic assays are linked to the mode of action of the drug and the employed test methods, we also evaluated the cytotoxic activity of the four compounds with the MTT cell proliferation assay. While the MTT assay gave higher $\mathrm{GI}_{50}$ values for $\mathbf{1} \mathbf{u}, \mathbf{1} \mathbf{w}$ and $\mathbf{3 d}$, the $\mathrm{SRB}$ assay gave higher $\mathrm{GI}_{50}$ values for $\mathbf{2 e}$ (Table 2). As both methods (SRB and MTT) gave $\mathrm{GI}_{50}$ values of the same order of magnitude (1-10 $\mu \mathrm{M})$, it can be concluded that the determined concentration range is the effective level of cytotoxicity of the four compounds.

In comparison to cytarabine and doxorubicin (reference drugs), two currently used conventional anti-cancer drugs, the four most cytotoxic compounds $1 \mathbf{u}, \mathbf{1 w}, \mathbf{2 e}$ and $\mathbf{3 d}$ displayed lower cytotoxicities (Table 2). Based on the results obtained by the MTT assay, only compound $\mathbf{2 e}$ approximated the cytotoxic level of doxorubicin. However, a previous report showed that cytarabine displayed lower cytotoxic activity with $\mathrm{GI}_{50}$ values of 3-5 $\mu \mathrm{M}$ when determined with the SRB assay. ${ }^{[22]}$ Based on this, it can be assumed that the four compounds exhibited similar cytotoxic activity levels as compared with cytarabine.

Overall, tumour cells were found to be more sensitive to all of the compounds tested than normal cells (Table 2). This observation indicates that cinchona alkaloid derivatives interfere with the replication of rapidly dividing cancer cells that are generally more susceptible to mitotic reagents than slow dividing normal cells. It is most likely that the compounds cause DNA damage that lead to cell death by apoptosis (see section 3.2). To determine the selectivity for the four most cytotoxic derivatives $\mathbf{1 u}, \mathbf{1 w}, \mathbf{2 e}$ and $\mathbf{3 d}$, selectivity indices (SIs) were calculated as the ratio of the $\mathrm{GI}_{50}$ on the normal $\mathrm{HDF}$ cell line to the $\mathrm{GI}_{50}$ on the respective tumour cell line (Table 3). We calculated the SI only for $\mathbf{1 u}, \mathbf{1 w}, \mathbf{2 e}$ and $\mathbf{3 d}$ because these four compounds fulfil the pre-screen criterion for new anti-cancer agents 
according to the National Cancer Institute (predetermined threshold inhibition concentration of $10 \mu \mathrm{M}) .{ }^{[23]}$ As cytotoxic compounds are usually not very selective, an SI of $>3$ is generally considered to be good. ${ }^{[24,25]}$ According to the results of the SRB assay, the derivatives $\mathbf{1 u}$ and 2e displayed SI values that were close to or greater than 3 for the four tumour cell lines tested (Table 3) suggesting that both compounds could be interesting candidates for further drug development. Derivative 1w had SI values less than 3 for the four tumour cell lines (Table 3) indicating that this compound exhibited some general toxicity. The quaternary ammonium salt 3d had a surprisingly high SI value for the lung cancer cell line A-549 only (Table 3). The SI values calculated from the data of the MTT assay were generally lower. Only 2a had an SI value of $>2$ for HeLa and A-59 cells (Table 2). On the other hand, the reference drugs cytarabine and doxorubicin showed SI values slightly higher than 2 for five tumour cell lines tested.

\subsection{Induction of apoptosis by compounds $1 u, 1 w, 2 e$, and $3 d$}

Since cinchona alkaloids have been shown to be able to trigger apoptosis in cancer cells, ${ }^{[5,26]}$ we were wondering whether the cytotoxic action of the four most potent derivatives was due to the induction of programmed cell death. The ability of compounds $1 \mathbf{u}, \mathbf{1 w}, \mathbf{2 e}$ and $3 \mathbf{d}$ to induce apoptosis was investigated with five cancer cell lines (HeLa, KB, A-549, U-87 and Hep-G2). Cells were treated with three different concentrations of each compound $(0.1$ $\mu \mathrm{g} / \mathrm{ml}, 1 \mu \mathrm{g} / \mathrm{ml}$ and $10 \mu \mathrm{g} / \mathrm{ml}$ ) and fragmentation of DNA as indicator for apoptosis was determined using a cell death ELISA. All four compounds induced apoptosis to a similar extent in all five cancer cell lines (Figure 1). A significant increase in the apoptotic index was found for all compounds with increasing concentration indicating that the induction of apoptosis was dose-dependent. At the lower concentrations of 0.1 and $1 \mu \mathrm{g} / \mathrm{ml}, \mathbf{3 d}$ was the most effective compound in inducing apoptosis with mean apoptotic indices of 1.77 and 3.92, respectively. At the higher concentration of $10 \mu \mathrm{g} / \mathrm{ml}, \mathbf{2 e}$ proved to be the most potent apoptosis-inducing derivative with a mean apoptotic index of 6.97 .

This article is protected by copyright. All rights reserved. 
Although the underlying mechanisms of the derivatives in triggering apoptosis in cancer cells remains unknown, studies with their unmodified counterparts may provide some clues to possible modes of action. For example, cinchona alkaloids have been shown to intercalate into DNA which can trigger apoptosis. ${ }^{[26]}$ Cinchonine has been reported to induce programmed cell death in cancer cells through competitive binding of TRAF6 leading to subsequent inhibition of AKT and TAK1 signalling pathways. ${ }^{[5]}$ Quinine was found to trigger its apoptotic effect through the inhibition of the NF- $\mathrm{KB}$ signalling pathway via reduction of Bcl 2 and mutant p53 and simultaneous up-regulation of caspase- 3 and Bax. ${ }^{[27]}$

\subsection{Trypanotoxicity of cinchona alkaloid derivatives}

Since compounds that display anti-cancer activity often also exhibit trypanocidal activity, ${ }^{[28]}$ we tested the cinchona alkaloid derivatives for their activity to inhibit the growth of bloodstream forms of T. b. brucei as well. The unmodified cinchona alkaloids 1a-d (quinine, quinidine, cinchonine and cinchonidine, respectively) showed similar antitrypanosomal activities with $\mathrm{GI}_{50}$ values in the low to mid micromolar range and MIC values of 10 to 100 $\mu \mathrm{M}$ as previously reported (Table 4). ${ }^{[6,29]}$ Most derivatives displayed similar or lower trypanocidal activity than their unmodified counterparts (Table 4). Exceptions were compounds 1n, 10 and $\mathbf{2 a}$, which showed no activity against trypanosomes with MIC and $\mathrm{GI}_{50}$ values $>100 \mu \mathrm{M}$, and compounds $\mathbf{2 e}$ and $\mathbf{3 d}$, which exhibited enhanced trypanocidal activity with MIC values below $10 \mu \mathrm{M}$ and $\mathrm{GI}_{50}$ values in the sub-micromolar range (Table 4). When compared with the MIC value and the $\mathrm{GI}_{50}$ value of suramin (Table 4; reference drug), one of the drugs used in the treatment of sleeping sickness, compounds $2 \mathbf{e}$ and $\mathbf{3 d}$ were, however, about 10 times less trypanocidal. Interestingly, these two compounds were among the four derivatives that were highly active against the six cancer cell lines (see Table 2). The selectivity of the cinchona alkaloid derivatives was determined with human leukaemia HL-60 cells because their sensitivity for approved trypanocides is well established. ${ }^{[6,30]}$ Most compounds including the unmodified cinchona alkaloids showed no

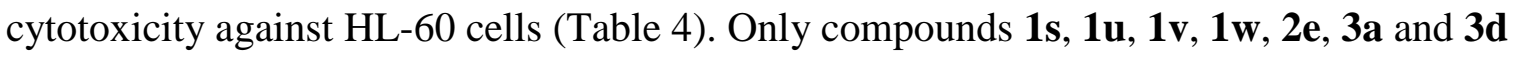


displayed different levels of cytotoxic activity against the leukaemia cells with $\mathrm{GI}_{50}$ values in the mid- to low-micromolar range. As the most trypanocidal compounds $\mathbf{2 e}$ and $\mathbf{3 d}$ were also quite cytotoxic for HL-60 cells, their SI were only moderate (just below 10) (Table 4). For comparison, drugs used for treatment of sleeping sickness have much higher SIs. ${ }^{[6,30]}$ For example, the reference drug suramin displayed no cytotoxicity towards HL-60 cell and accordingly the MIC and $\mathrm{GI}_{50}$ ratios of this trypanocide were >1000 and >2941, respectively (Table 4). However, as HL-60 cells are cancer cells, the selectivity of the two compounds may be overestimated. In fact, the most trypanocidal compound $2 \mathrm{e}$ was 1.5 to 6 times less cytotoxic towards non-malignant HDF cells than towards HL-60 cells (Table 2 and 4). Based on this, the selectivity index of compound $\mathbf{2 e}$ would be 15-60. Hence, derivative $2 \mathbf{e}$ almost fulfils the activity criteria for drug candidates for African trypanosomiaisis $\left(\mathrm{GI}_{50}<1 \mu \mathrm{M}\right.$; SI $>100){ }^{[33]}$

\section{CONCLUSION}

This investigation has shown that naturally occurring cinchona alkaloids can be considered as a source for an easy construction of derivatives with increased cytotoxic and trypanocidal activity. Of the four compounds (1u, 1w, 2e and 3d) that displayed remarkable cytotoxicity, two derivatives ( $\mathbf{2 e}$ and $\mathbf{3 d}$ ) exhibited also strong antitrypanosomal activity. The common structural feature of all four compounds was the replacement of their C-9 hydroxy group to either $O$-carbamates $(\mathbf{1 u}$ and $\mathbf{1 w})$, to thiourea (2e), or to $O$-allyl ether $(\mathbf{3 d})$. Thus, it seems that appropriate modification of the C-9 hydroxy group is crucial for improving the antiproliferative activity of cinchona alkaloid derivatives. In addition, a particular stereochemistry of the alkaloid moiety is not a prerequisite for the activity as three $(\mathbf{1} \mathbf{u}, \mathbf{1} \mathbf{w}$ and 3d) out of the four compounds had $8 S, 9 R$ configuration (as in quinine or cinchonidine) but the 9-epimeric compound 2e with $8 S, 9 S$ configuration displayed also high potency. Both 9-O-protected quaternary salts and 9-thiourea derivatives turned out to be the promising candidates for further activity optimization. Studies in this area are in progress and will be presented in due course.

This article is protected by copyright. All rights reserved. 


\section{CONFLICT OF INTEREST}

The authors declare that they have no conflicts of interests.

\section{ORCID}

Dietmar Steverding http://orcid/0000-0002-0050-7771

\section{FIGURE LEGENDS}

Figure 1 Induction of apoptosis in cancer cells by cinchona alkaloid derivatives $1 \mathbf{u}(\mathrm{A}), \mathbf{1}$ (B), 2e (C) and 3d (D). Five cancer cell lines (KB, HeLa, A-549, Hep-G2 and U-87) were treated with the test compounds at concentrations of $0.1,1$ and $10 \mu \mathrm{g} / \mathrm{ml}$ for $4 \mathrm{~h}$. Apoptosis was determined with a cell death ELISA. The apoptotic index refers to the ratio of nucleosome enrichment in treated cells to untreated (control) cells. Data shown are means \pm SD from three independent experiments.

\section{REFERENCES}

[1] P. Gurung, P. De, J. Pharmacogn. Phytochem. 2017, 6, 162.

[2] K. M. Kacprzak, in Natural Products (Eds. K. G. Ramawat, J. M. Merillon), Springer, Berlin, Heidelberg 2013, p. 605.

[3] P. Genne, M. T. Dimanche-Boitrel, R. Y. Mauvernay, G. Gutierrez, O. Duchamp, J. M. Petit, F. Martin, B. Chauffert, Cancer Res. 1992, 52, 2787.

[4] M. Krishnaveni, K. Suresh, Int. J. Curr. Res. Aca. Rev. 2015, 3, 169.

[5] Y. Qi, A. R. Pradipta, M. Li, X. Zhao, L. Lu, X. Fu, J. Wei, R. P. Hsung, K. Tanaka, L. Zhou, J. Exp. Clin. Cancer Res. 2017, 36, 35.

[6] K. Merschjohann, F. Sporer, D. Steverding, M. Wink, Planta Med. 2001, 67, 623.

[7] D. Steverding, Parasit. Vectors 2008, 1, 3.

[8] D. Steverding, in Arthropod Borne Diseases (Ed. C. B. Marcondes), Springer International Publishing, Cham, 2017, p. 277. 
[9] A. Nakano, S. Kawahara, S. Akamatsu, K. Morokuna, M. Nakatani, Y. Iwabuchi, K. Takahashi, J. Ishihara, S. Hatakeyama, Tetrahedron 2006, 62, 381.

[10] K. M. Kacprzak, W. Lindner, N. M. Maier, Chirality 2008, 20, 441.

[11] W. Koenigs, Justus Liebigs Ann. Chem. 1906, 347, 143.

[12] J. N. Alumasa, A. P. Gorka, L. B. Casabianca, E. Comstock, A. C. de Dios, P. D. Roepe, J. Inorg. Biochem. 2011, 105, 467.

[13] W. B. Yi, X. Huang, Z. Zhang, D. R. Zhu, C. Cai, W. Zhang, Beilstein J. Org. Chem. 2012, 8, 1233.

[14] K. M. Kacprzak, N. M. Maier, W. Lindner, J. Chromatogr. A 2011, 1218, 1452.

[15] S. Wu, J. Guo, M. Sohail, C. Cao, F. X. Chen, J. Fluor. Chem. 2013, 148, 19.

[16] E. J. Corey, M. C. Noe, Org. Synth. 2003, 80, 38.

[17] L. V. Rubinstein, R. H. Shoemaker, K. D. Paull, R. M. Simon, S. Tosini, P. Skehan, D. A. Scudiero, A. Monks, M. R. Boyd, J. Nat. Cancer Inst. 1990, 82, 1113.

[18] H. Hirumi, K. Hirumi, J. J. Doyle, G. A. M. Cross, Parasitology 1980, 80, 371.

[19] S. J. Collins, R. C. Gallo, R. E. Gallagher, Nature 1977, 270, 347.

[20] T. Baltz, D. Baltz, C. Giroud, J. Crockett, EMBO J. 1985, 4, 1273.

[21] W. Huber, J. C. Koella, Acta Trop. 1993, 55, 257.

[22] M. Lewandowska, P. Ruszkowski, K. Chojnacka, N. Kleczewska, M. Hoffmann, K. Kacprzak, L. Celewicz, Bioorg. Med. Chem. 2016, 24, 2330.

[23] A. M. Burger, H.-H. Fiebig, in Handbook of Anticancer Pharmacokinetics and Pharmacodynamics (Eds. M. A. Rudek, C. H. Chau, W. Figg, H. L. McLeod), Springer, New York, 2014, p. 23.

[24] C. Bézivin, S. Tomasi, F. Lohézic-Le Dévéhat, J. Boustie, Phytomedicine 2003, 10, 499.

[25] S. Machana, N. Weerapreeyakul, S. Barusrux, A. Nonpunya, B. Sripanidkulchai, T. Thitimetharoch, Chin. Med. 2011, 6, 39.

[26] V. Rosenkranz, M. Wink, Z. Naturforsch. C 2007, 62, 458.

[27] M. Krishnaveni, K. Suresh, R. Arunkumar, Bangladesh J. Pharmacol. 2016, 11, 593.

[28] M. Q. Klinkert, V. Heussler, Mini Rev. Med. Chem. 2006, 6, 131. 
[29] A. Leverrier, J. Bero, J. Cabrera, M. Frédérich, J. Quetin-Leclercq, J. A. Palerno, Eur. J. Med. Chem. 2015, 100, 10.

[30] C. R. Caffrey, D. Steverding, R. K. Swenerton, B. Kelly, D. Walshe, A. Debnath, Y. M. Zhou, P. S. Doyle, A. T. Fafarman, J. A. Zorn, K. M. Land, J. Beauchene, K. Schreiber, H. Moll, A. Ponte-Sucre, T. Schirmeister, A. Saravanamuthu, A. H. Fairlamb, F. E. Cohen, J. H. McKerrow, J. L. Weisman, B. C. May, Antimicrob. Agents Chemother. 2007, 51, 2164.

[31] S. Nwaka, A. Hudson, Nat. Rev. Drug Discov. 2006, 5, 941.

\section{NOT E S}

${ }^{a}$ Originally, the KB cell line was derived from an epidermal carcinoma of the mouth of an adult male Caucasian, but was subsequently contaminated with HeLa cells. As KB cells are indistinguishable from HeLa cells by DNA fingerprinting, KB cells should be considered as derived from HeLa cells. 
TABLE 1 Chemical structure of cinchona alkaloids (1a-e) and their derivatives (1f-w, 2a-e, 3a-d)<smiles>[R]c1ccc2nccc(C([R2])[C@H]3CN4CCC3C4[R])c2c1</smiles>

1a-w, 2e

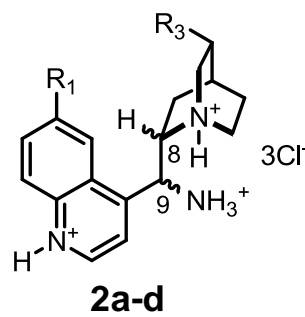

2a-d

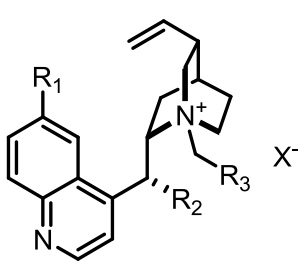

3a-d

\section{Configuration}

$\begin{array}{lllllll}\text { Compound } & \text { at C-8 and C-9 } & \mathbf{R}_{1} & \mathbf{R}_{2} & \mathbf{R}_{3} & \mathrm{X}^{-}\end{array}$

Unmodified cinchona alkaloids

$\begin{array}{lllll}\text { 1a } & 8 S, 9 R & \mathrm{OMe} & \mathrm{OH} & \text { vinyl } \\ \text { 1b } & 8 R, 9 S & \mathrm{OMe} & \mathrm{OH} & \text { vinyl } \\ \text { 1c } & 8 R, 9 S & \mathrm{H} & \mathrm{OH} & \text { vinyl } \\ \text { 1d } & 8 S, 9 R & \mathrm{H} & \mathrm{OH} & \text { vinyl } \\ \text { 1e } & 8 R, 9 R & \mathrm{OMe} & \mathrm{OH} & \text { vinyl }\end{array}$

Modification of vinyl group

$\begin{array}{lllllr}\mathbf{1 f} & 8 S, 9 R & \mathrm{OMe} & \mathrm{OH} & \text { ethyl } & \text { - } \\ \mathbf{1 g} & 8 R, 9 S & \mathrm{OMe} & \mathrm{OH} & \text { ethyl } & \text { - } \\ \mathbf{1 h} & 8 R, 9 R & \mathrm{OMe} & \mathrm{OH} & \text { ethyl } & \text { - } \\ \mathbf{1 i} & 8 S, 9 R & \mathrm{OH} & \mathrm{OH} & \text { ethyl } & - \\ \mathbf{1 j} & 8 R, 9 S & \mathrm{OH} & \mathrm{OH} & \text { ethyl } & - \\ \mathbf{1 k} & 8 R, 9 S & \mathrm{H} & \mathrm{OH} & \text { ethyl } & - \\ \mathbf{1 1} & 8 S, 9 R & \mathrm{OMe} & \mathrm{OH} & \text { ethynyl } & - \\ \mathbf{1 m} & 8 R, 9 S & \mathrm{OMe} & \mathrm{OH} & \text { ethynyl } & - \\ \mathbf{1 n} & 8 R, 9 S & \mathrm{H} & \mathrm{OH} & \text { COOH } & - \\ \mathbf{1 0} & 8 S, 9 R & \mathrm{H} & \mathrm{OH} & \text { COOH } & - \\ \mathbf{1 p} & 8 S, 9 R & \mathrm{H} & \mathrm{OH} & \text { COOEt } & \text { - }\end{array}$

Modification of 9-hydroxy group

$\begin{array}{lllll}1 \mathbf{1 q} & 8 R & \mathrm{OMe} & \mathrm{H} & \text { ethyl } \\ \mathbf{1 r} & 8 S, 9 R & \text { OMe } & \text { OAc } & \text { vinyl }\end{array}$




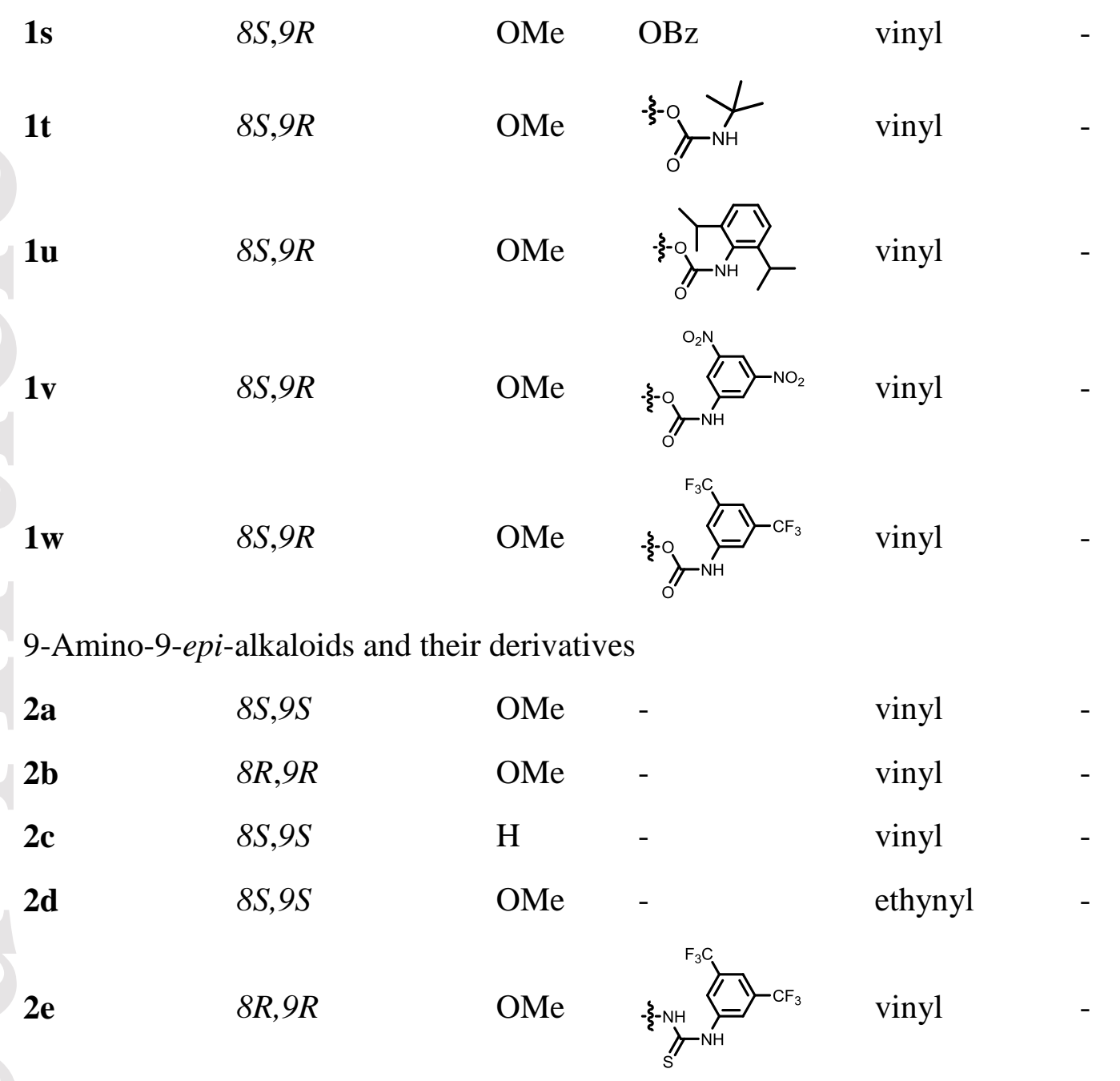

Quaternary ammonium salt derivatives

3a $35,9 R \quad$ OMe


TABLE 2 In vitro activity of cinchona alkaloid derivatives against tumour and normal cells ${ }^{\mathrm{a}}$

Tumour cells

\section{Compound}

Unmodified cinchona alkaloids

\section{1a}

$1 \mathrm{~b}$

1c

$1 d$

1e

Modification of vinyl group

1f 1 .

1h

1i

1j

$1 \mathrm{k}$

11

$1 \mathrm{~m}$

$1 n$

10

$1 p$

Modification of 9-hydroxy group

$1 q$
$1 r$
$1 s$
$1 t$

$145 \pm 1$

$60.3 \pm 1.7$

$94.7 \pm 1.5$

$73.2 \pm 0.8$

$83.6 \pm 0.1$

$76.8 \pm 0.2$

$40.3 \pm 0.4$
$229 \pm 1$

$52.4 \pm 0.2$

$149 \pm 1$

$86.4 \pm 0.1$

$122 \pm 1$

\section{MCF-7}

A-549

$56.4 \pm 1.2$ $37.0 \pm 0.2$

$155 \pm 1$

$65.9 \pm 0.3$

$64.7 \pm 0.2$

$82.7 \pm 0.6$

$69.8 \pm 0.2$

$58.5 \pm 1.2$

$73.3 \pm 0.2$

$38.4 \pm 1.6$

$169 \pm 1$

$49.6 \pm 2.6$

$140 \pm 1$

$92.8 \pm 2.6$

$102 \pm 1$

$56.7 \pm 0.3$

$158 \pm 1$

$73.7 \pm 1.1$

$105 \pm 1$

$72.2 \pm 0.1$

$\begin{array}{ll}55.5 \pm 0.1 & \text { n.d. } \\ 36.4 \pm 0.1 & \text { n.d. } \\ 129 \pm 1 & \text { n.d. } \\ 96.8 \pm 0.7 & \text { n.d. } \\ 64.7 \pm 1.4 & 67.5 \pm 0.1 \\ & \\ 82.7 \pm 1.0 & 66.8 \pm 0.1 \\ 75.1 \pm 1.7 & 55.8 \pm 0.1 \\ 58.2 \pm 0.4 & 58.2 \pm 0.9 \\ 70.7 \pm 0.1 & 52.5 \pm 0.9 \\ 38.4 \pm 0.2 & 25.9 \pm 1.1 \\ 194 \pm 1 & 173 \pm 2 \\ 49.6 \pm 0.4 & \text { n.d. } \\ 153 \pm 1 & \text { n.d. } \\ 92.8 \pm 0.5 & 75.6 \pm 0.2 \\ 112 \pm 1 & 112 \pm 1 \\ 55.8 \pm 0.1 & 32.3 \pm 0.1\end{array}$

$137 \pm 1 \quad 110 \pm 1$

$59.8 \pm 0.2$

$35.2 \pm 0.1$

$107 \pm 1 \quad 74.9 \pm 0.4$

$59.5 \pm 1.8 \quad 50.5 \pm 0.3$

n.d.

n.d.

n.d.

n.d.

n.d.

n.d.

n.d.

n.d.

n.d.

n.d.

n.d.

n.d.

n.d.

n.d.

n.d.

n.d.

n.d.

n.d.

n.d.

n.d.

Normal cells

HDF CHO

$\begin{array}{ll}160 \pm 1 & \text { n.d. } \\ 151 \pm 1 & \text { n.d. } \\ 397 \pm 1 & \text { n.d. } \\ 236 \pm 1 & \text { n.d. } \\ 120 \pm 1 & 111 \pm 3\end{array}$

$123 \pm 1 \quad 89.1 \pm 0.1$

$184 \pm 1 \quad 211 \pm 2$

$85.8 \pm 0.1 \quad 65.9 \pm 1.5$

$89.6 \pm 0.4 \quad 102 \pm 1$

$61.8 \pm 0.3 \quad 54.4 \pm 1.0$

$273 \pm 1 \quad 293 \pm 1$

$436 \pm 1 \quad$ n.d.

$270 \pm 1$ n.d.

$101 \pm 4 \quad 102 \pm 1$

$193 \pm 1 \quad 195 \pm 1$

$61.7 \pm 1.8 \quad 76.7 \pm 0.1$

$284 \pm 1 \quad 263 \pm 1$

$131 \pm 1 \quad 114 \pm 1$

$145 \pm 1 \quad 145 \pm 1$

$89.7 \pm 0.1 \quad 89.7 \pm 0.1$

This article is protected by copyright. All rights reserved. 


\begin{tabular}{lllllllll}
$\mathbf{1 u}$ & $3.98 \pm 0.02$ & $3.79 \pm 2.07$ & $3.22 \pm 0.16$ & $0.95 \pm 0.03$ & n.d. & n.d. & $11.6 \pm 0.1$ & $11.4 \pm 0.4$ \\
$\mathbf{1 u}$ (MTT) & $5.65 \pm 0.06$ & $5.80 \pm 2.03$ & n.d & $5.39 \pm 0.23$ & $4.06 \pm 0.21$ & $5.20 \pm 0.63$ & $7.36 \pm 0.17$ & n.d. \\
$\mathbf{1 w}$ & $3.11 \pm 0.12$ & $1.90 \pm 0.05$ & $2.24 \pm 0.01$ & $2.24 \pm 0.31$ & n.d. & n.d. & $4.31 \pm 0.05$ & $4.83 \pm 0.91$ \\
$\mathbf{1 w}$ (MTT) & $7.44 \pm 0.07$ & $7.06 \pm 0.02$ & n.d. & $7.56 \pm 0.12$ & $7.11 \pm 0.03$ & $8.47 \pm 0.76$ & $10.5 \pm 0.7$ & n.d. \\
9-Amino-9-epi-alkaloids and their derivatives & & & & & & \\
2a & $15.7 \pm 1.0$ & $13.9 \pm 0.4$ & $15.5 \pm 1.6$ & $13.2 \pm 0.5$ & n.d. & n.d. & $25.4 \pm 0.1$ & $27.1 \pm 0.8$ \\
$\mathbf{2 b}$ & $18.5 \pm 0.4$ & $18.5 \pm 0.9$ & $18.5 \pm 0.8$ & $16.9 \pm 0.4$ & n.d. & n.d. & $38.1 \pm 0.1$ & $41.6 \pm 0.1$ \\
$\mathbf{2 c}$ & $15.1 \pm 0.3$ & $14.9 \pm 0.5$ & $13.2 \pm 0.1$ & $12.4 \pm 0.1$ & n.d. & n.d. & $21.1 \pm 2.6$ & $21.1 \pm 0.9$ \\
$\mathbf{2 e}$ & $4.88 \pm 0.6$ & $2.86 \pm 0.23$ & $3.20 \pm 0.03$ & $2.86 \pm 0.03$ & n.d. & n.d. & $19.3 \pm 0.8$ & $18.5 \pm 0.1$ \\
2e (MTT) & $2.91 \pm 0.07$ & $1.79 \pm 0.05$ & n.d. & $1.98 \pm 1.40$ & $3.13 \pm 0.25$ & $1.96 \pm 1.19$ & $4.76 \pm 0.13$ & n.d. \\
Quaternary ammonium salt derivatives & & & & & & \\
3d & $1.32 \pm 0.02$ & $1.32 \pm 0.08$ & $1.32 \pm 0.01$ & $0.20 \pm 0.11$ & n.d. & n.d. & $2.64 \pm 0.15$ & $1.82 \pm 0.49$ \\
3d (MTT) & $6.62 \pm 1.27$ & $6.92 \pm 0.10$ & n.d. & $8.01 \pm 0.03$ & $7.61 \pm 0.02$ & $6.89 \pm 0.81$ & $11.8 \pm 0.1$ & n.d. \\
Reference drugs & & & & & & & \\
cytarabine (MTT) & $0.62 \pm 0.04$ & $0.66 \pm 0.12$ & n.d. & $0.45 \pm 0.70$ & $0.53 \pm 0.25$ & $0.78 \pm 0.37$ & $1.32 \pm 0.49$ & n.d. \\
doxorubicin (MTT) & $1.25 \pm 0.13$ & $1.14 \pm 0.29$ & n.d. & $1.31 \pm 0.02$ & $1.34 \pm 0.24$ & $1.42 \pm 0.04$ & $2.93 \pm 0.09$ & n.d. \\
\hline
\end{tabular}

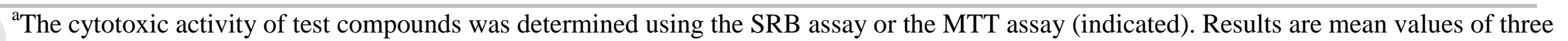
independent experiments and expressed as $\mathrm{GI}_{50}$ values $\pm \mathrm{SD}$ in $\mu \mathrm{M}$. KB, human cervix carcinoma derived from HeLa cells; HeLa, human cervix carcinoma; MCF-7, human breast cancer; A-549, human lung cancer; HepG2, human hepatocyte carcinoma; U-87, human glioblastoma: HDF, human dermal fibroblast; $\mathrm{CHO}$, Chinese hamster ovary cells.

${ }^{b}$ n.d., not determined.

This article is protected by copyright. All rights reserved. 
TABLE 3 Selectivity indices for the most active compounds (with $\mathrm{GI}_{50}$ values $<10 \mu \mathrm{M}$ )

\begin{tabular}{|c|c|c|c|c|c|c|}
\hline \multirow[b]{2}{*}{ Compound } & \multicolumn{6}{|l|}{$\mathbf{S I}^{\mathrm{a}}$} \\
\hline & $\overline{K B}$ & HeLa & MCF-7 & A-549 & Hep-G2 & U-87 \\
\hline $1 \mathbf{u}$ & 2.9 & 3.1 & 3.6 & 12.2 & n.d. ${ }^{b}$ & n.d. \\
\hline 1u (MTT) & 1.3 & 1.3 & n.d. & 1.4 & 1.8 & 1.4 \\
\hline $\mathbf{1 w}$ & 1.4 & 2.3 & 1.9 & 1.9 & n.d. & n.d. \\
\hline 1w (MTT) & 1.4 & 1.5 & n.d. & 1.4 & 1.5 & 1.2 \\
\hline $2 e$ & 4.0 & 6.7 & 6.0 & 6.7 & n.d. & n.d. \\
\hline $\mathbf{2 e}(\mathrm{MTT})$ & 1.6 & 2.8 & n.d. & 2.4 & 1.5 & 2.4 \\
\hline 3d & 2.0 & 2.0 & 2.0 & 13.2 & n.d. & n.d. \\
\hline 3d (MTT) & 1.8 & 1.7 & n.d. & 1.5 & 1.6 & 1.7 \\
\hline cytarabine (MTT) & 2.1 & 2.0 & n.d. & 2.9 & 2.5 & 1.7 \\
\hline doxorubicin (MTT) & 2.3 & 2.6 & n.d. & 2.2 & 2.2 & 2.1 \\
\hline
\end{tabular}

This article is protected by copyright. All rights reserved. 
TABLE 4 In vitro activity of cinchona alkaloid derivatives against $T$. $b$. brucei and HL-60 cells

T. b. brucei

\section{Compound}

HL-60 cells

$\begin{array}{ll}\mathrm{MIC}^{\mathrm{a}} & \mathrm{GI}_{50}^{\mathrm{b}}\end{array}$

Unmodified cinchona alkaloids

1a

10

$3.26 \pm 0.32$

$2.62 \pm 0.26$

$3.61 \pm 0.29$

$23.8 \pm 10.1$

$44.1 \pm 9.1$

1e

Modification of vinyl group

$1 \mathbf{f}$

19

1h

1i

$\mathbf{1 j}$

$1 \mathrm{k}$

11

$1 \mathrm{~m}$

1n

10

$1 p$
10-100 (40)

10

100

100

10

$10-100(40)$

100

100

$>100$

$>100$

100
$3.75 \pm 0.93$

$>100$

$>100$

$2.72 \pm 0.35$

$>100$

$>100$

$24.8 \pm 3.2$

$>100$

$>100$

$26.2 \pm 4.7>100$

$>100$

$5.58 \pm 3.05$

$>100$

$>100$

$>100$

$>100$

$>100$

$>100$

$>100$

$>100$

$>100$

$>100$

$>100$

$>100$

$>100$

$>100$

$>1-10$

$>26$

$>10$

$>36$

$>1$

$>4.0$

$>1$

$>3.8$

$>10$

$>17$

$>1-10$

$>20$

$>1$

$>4.4$

$>1$

$>3.4$

n.a.

n.a.

n.a.

n.a.

$>1$

$>2.8$

Modification of 9-hydroxy group

\begin{tabular}{|c|c|c|c|c|c|c|}
\hline $1 q$ & 100 & $27.2 \pm 6.4$ & $>100$ & $>100$ & $>1$ & $>3.6$ \\
\hline $1 \mathbf{r}$ & 100 & $16.5 \pm 8.7$ & $>100$ & $>100$ & $>1$ & $>6.0$ \\
\hline $1 \mathrm{~s}$ & $10-100(40)$ & $3.44 \pm 0.72$ & 100 & $35.7 \pm 2.6$ & $1-10$ & 10.4 \\
\hline $1 t$ & 100 & $22.2 \pm 7.7$ & $>100$ & $>100$ & $>1$ & $>4.5$ \\
\hline & 100 & $26.7 \pm 4.7$ & 100 & $37.6 \pm 1.7$ & 1 & 1.4 \\
\hline 1s & 10 & $3.24 \pm 1.44$ & 100 & $35.5 \pm 1.2$ & 10 & 11.0 \\
\hline
\end{tabular}

This article is protected by copyright. All rights reserved. 
9-Amino-9-epi-alkaloids and their derivatives

$\begin{array}{lllllll}\mathbf{2 a} & >100 & >100 & >100 & >100 & \text { n.a. } & \text { n.a. } \\ \mathbf{2 b} & 100 & 30.6 \pm 5.0 & >100 & >100 & >1 & >3.2 \\ \mathbf{2 c} & 100 & 26.5 \pm 6.8 & >100 & >100 & >1 & >3.7 \\ \mathbf{2 d} & >100 & 48.1 \pm 21.6 & >100 & >100 & \text { n.a. } & >2.0 \\ \mathbf{2 e} & 1 & 0.33 \pm 0.04 & 10 & 3.16 \pm 0.10 & 10 & 9.6\end{array}$

Quaternary ammonium salt derivatives

$\begin{array}{lllllll}\text { 3a } & 10 & 3.22 \pm 0.22 & 100 & 31.9 \pm 1.2 & 10 & 9.9 \\ \text { 3b } & 100 & 38.5 \pm 1.9 & >100 & >100 & >1 & >2.5 \\ \text { 3c } & 100 & 43.5 \pm 5.2 & >100 & >100 & >1 & >2.2 \\ \text { 3d } & 1-10(7) & 0.41 \pm 0.17 & 10 & 3.97 \pm 0.43 & 1-10 & 9.7 \\ \text { Reference drug } & & & & & >1000 & >2941 \\ \text { suramin } & 0.1 & 0.034 \pm 0.002 & >100 & >100 & \end{array}$

${ }^{\mathrm{a}} \mathrm{MIC}$ values are expressed in $\mu \mathrm{M}$. In case that not all three experiments gave the same MIC value, a range from the lowest to the highest MIC values observed is instead provided with the average MIC value in parenthesis.

${ }^{\mathrm{b}} \mathrm{GI}_{50}$ values are expressed as mean values $\pm \mathrm{SD}$ in $\mu \mathrm{M}$.

${ }^{\mathrm{c}}$ Defined as $\mathrm{MIC}_{(\mathrm{HL}-60)} / \mathrm{MIC}_{(T .}$ b. brucei) .

${ }^{\mathrm{d}}$ Defined as $\mathrm{GI}_{50(\mathrm{HL}-60)} / \mathrm{GI}_{50(\text { T. b. brucei })}$.

${ }^{\mathrm{e}}$ n.a., not assignable (since values for both HL-60 cell and T. b. brucei are $>100 \mu \mathrm{M}$ ). 


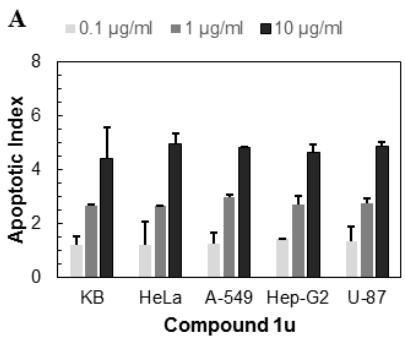

This article is protected by copyright. All rights reserved. 


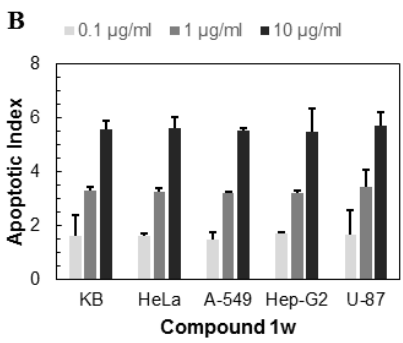

This article is protected by copyright. All rights reserved. 


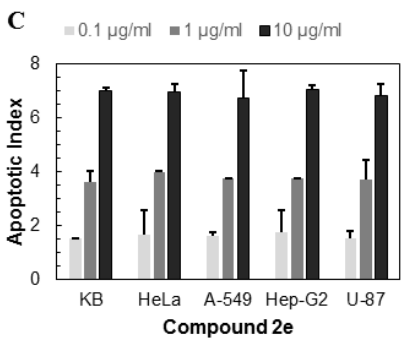

This article is protected by copyright. All rights reserved. 


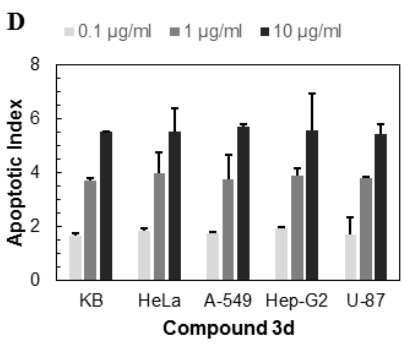

This article is protected by copyright. All rights reserved. 